\title{
The Prevention of Oxy Radical-Mediated Lung Tumorigenesis in Mice by Vitamin $\mathbf{E}$
}

\author{
Tomio ICHIKAWA ${ }^{1}$, Gaku IsHIKAwA ${ }^{2}$, and Tomohiro YANo ${ }^{1}$ \\ ${ }^{1}$ Division of Applied Food Research, \\ The National Institute of Health \& Nutrition, Tokyo 162, Japan, \\ ${ }^{2}$ Laboratory of Food Chemistry, \\ Faculty of Agriculture \& Veterinary Medicine, \\ Nihon University, Tokyo 154, Japan
}

\begin{abstract}
Summary This work was carried out to estimate the preventive effect of vitamin $\mathrm{E}$ on oxy radical-enhanced lung tumorigenesis in ddY mice. We have reported that oxy radicals could be an important factor contributing to the promotive effect of glycerol on 4-nitroquinoline 1oxide (4NQO)-induced lung tumorigenesis (1). The glycerol-promoted lung tumorigenesis of mice treated with 4NQO was reduced in mice feeding on excessive vitamin $\mathrm{E}$ in this study. The levels of nuclear thiobarbituric acid reactive substances (TBARS) and oxidative damage of DNA estimated as DNA single strand breaks (DNA-SSB) were significantly higher in the lungs of mice treated with $4 \mathrm{NQO}+$ glycerol than in those treated with $4 \mathrm{NQO}$ at 4 weeks after $4 \mathrm{NQO}$ administration, This increase was suppressed by the feeding of excessive vitamin $\mathrm{E}$ for 4 weeks after 4 NQO injection. At 23 weeks after 4 NQO injection, the feeding of excessive vitamin $\mathrm{E}$ for 4 and 23 weeks after $4 \mathrm{NQO}$ injection could cancel the promotive effect of glycerol on lung tumorigenesis. Additionally, the $\alpha$-tocopherol level in serum was related with the degree of lung tumorigenesis at 23 weeks after 4NQO injection. These findings suggest that vitamin $\mathrm{E}$ can act as a useful agent to protect mice from oxy radical-promoted lung tumorigenesis.
\end{abstract}

Key Words vitamin E, oxy radicals, lung tumorigenesis, mice

\section{INTRODUCTION}

Oxy radical and oxidative stress are believed to play an important role in carcinogenesis (2). Serious oxidative damage on nuclei may lead to oxidative damage of DNA such as DNA-SSB and the enhancement of carcinogenesis (3-5). Many epidemiological and experimental studies show that some antioxidants can reduce cancer risk in some organs (6). With respect to the inhibitory effect of vitamin $\mathrm{E}$, the results of epidemiology studies are 
contradictory at present (7). However, vitamin E is considered to act as a more effective antioxidant than other antioxidants like $\beta$-carotene at relatively higher oxygen partial pressure $(8)$. Since lung tissue is usually exposed to many oxidants and has a higher oxygen partial pressure than other tissues, vitamin E may be a useful antioxidant to protect lung tissues from oxidative stress.

Glycerol has been known to cause morphological changes in the bronchiolar non-ciliated (Clara) cell which is a possible progenitor cell of peripheral carcinoma in the lung and it promotes the development of lung tumors in ddY mice treated with 4 NQO $(9,10)$. In addition, our previous findings suggested that the rise of oxy radical formation and oxidative stress in the lungs was a key event to enhance 4NQO-induced lung tumorigenesis in ddY mice with glycerol $(1,11)$. Therefore, this study was undertaken to evaluate the preventive effect of vitamin $\mathrm{E}$ on the glycerol-related elevation of pulmonary oxidative stress and lung tumorigenesis in ddY mice treated with 4NQO.

\section{MATERIAL \& METHODS}

Animals \& Treatment. Six-week-old male, specific pathogen-free (SPF), ddY and A/J strain mice were maintained under conventional clean-rack systems at $22^{\circ} \mathrm{C}$ and $55 \%$ humidity and also on a 12 diurnal system. The mice were fed a control CE-2 diet and special CE-2 diet containing excessive vitamin E (Japan Clea, Tokyo, Japan). A five percent glycerol solution or sterilized water was given ad libitum. The mice were given a 4 NQO solution at a dose of $10 \mathrm{mg} / \mathrm{kg}$ body weight by a subcutaneous injection on the first experimental day (12).

Experimental design. Figure 1 shows this experimental design. The animals were divided into six groups (groups 1 to 6 ). Groups 3 to 6 were given 4 NQO on the first experimental day. Groups 2 and 4 to 6 received glycerol for 4 weeks after the 4 NQO injection. Groups 5 and 6 were fed a special CE- 2 diet for 4 and 23 weeks after the 4 NQO injection, respectively. At 4 weeks after the 4 NQO injection, each mouse in groups 3 to 5 was killed to determine the levels of DNASSB, nuclear TBARS and $\alpha$-tocopherol in the lungs. At 23 weeks after 4NQO injection, all mice were killed by exsanguination from the abdominal artery under pentobarbital anesthesia.

Tumor assay. The lungs were fixed by intracheal instillation of $10 \%$ buffered formalin. Tumors on the lung surface were scored under a dissecting microscope. All tumors observed in this experiment were adenoma.

Nuclei preparation \& Biochemical assay. Pulmonary nuclei were isolated by differential centrifugation (12). Lipid peroxidation of nuclei was estimated as the content of TBARS by the method of Uchiyama and Mihara (13), using malondialdehyde as the standard. The level of $\alpha$-tocopherol in nuclei was analyzed by high performance liquid chromatography with fluorometric detection (14). To measure DNA-SSB, the alkali unwinding assay of Morris and Shertzer (15) was used.

Data Analysis. Data were analyzed, where appropriate, by one-way analysis 


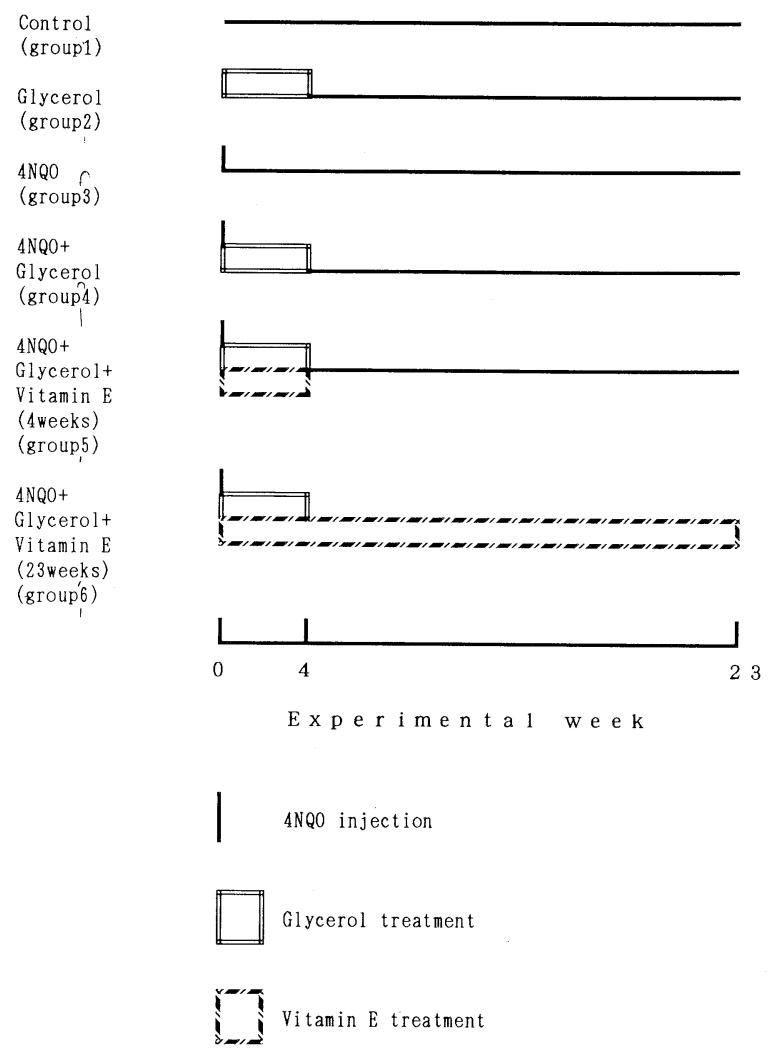

Fig. 1. Experimental design.

of variance followed by Duncan's multiple-range test or chi-square test. A $p$ value of 0.05 or less was considered to be significant.

\section{RESULTS}

Table 1 shows the results of the effect of vitamin $E$ on oxidative stress toward pulmonary nuclei. Nuclear oxidative stress (TBARS level) increased with a significant difference by glycerol treatment, and the increased level of TBARS returned to a level similar to that in the 4NQO-treated group. The $\alpha$-tocopherol level in pulmonary nuclei decreased slightly by glycerol treatment, and vitamin $\mathrm{E}$ treatment caused a significant increase in the level as compared to the $4 \mathrm{NQO}-$ and $4 \mathrm{NQO}+$ glycerol-treated groups. Lung DNA-SSB was significantly increased from $28.5 \%$ in the 4 NQO-treated group to $35.7 \%$ in the $4 \mathrm{NQO}+$ glycerol-treated group. However, the increase of DNA-SSB caused by glycerol 
Table 1. Nuclear TBARS, $\alpha$-tocopherol levels and oxidative damages of DNA in the lungs of ddY mice at 4 weeks after $4 \mathrm{NQO}$ injection.

\begin{tabular}{cccc}
\hline Article & \multicolumn{3}{c}{ Treatment group } \\
\cline { 2 - 4 } & $4 \mathrm{NQO}$ & $4 \mathrm{NQO}+$ Glycerol & $\begin{array}{c}\text { 4NQO }+ \text { Glycerol }+ \\
\text { Vitamin E }\end{array}$ \\
\hline $\begin{array}{c}\text { TBARS } \\
\text { (nmole/g lung) } \\
\alpha \text {-tocopherol } \\
(\mu \text { g/g lung) } \\
\text { DNA unwinding } \\
(\% \text { unwound DNA) }\end{array}$ & $0.38 \pm 0.08$ & $0.32 \pm 0.03$ & $1.40 \pm 016^{\mathrm{a}, \mathrm{b}}$ \\
\hline
\end{tabular}

All mice were given the 4NQO-mixture by subcutaneous injection on the first experimental day. The period of glycerol and/or vitamin $E$ treatment was 4 weeks after 4 NQO injection as mentioned above. Values are expressed as the mean \pm S.E. from 5 mice. ${ }^{a}$ Significant difference from 4 NQO. ${ }^{b}$ Significant difference from 4 NQO + Glycerol.

Table 2. Effect of feeding vitamin $\mathrm{E}$ on glycerol-enhanced lung tumorigenesis in ddY mice treated with $4 \mathrm{NQO}$.

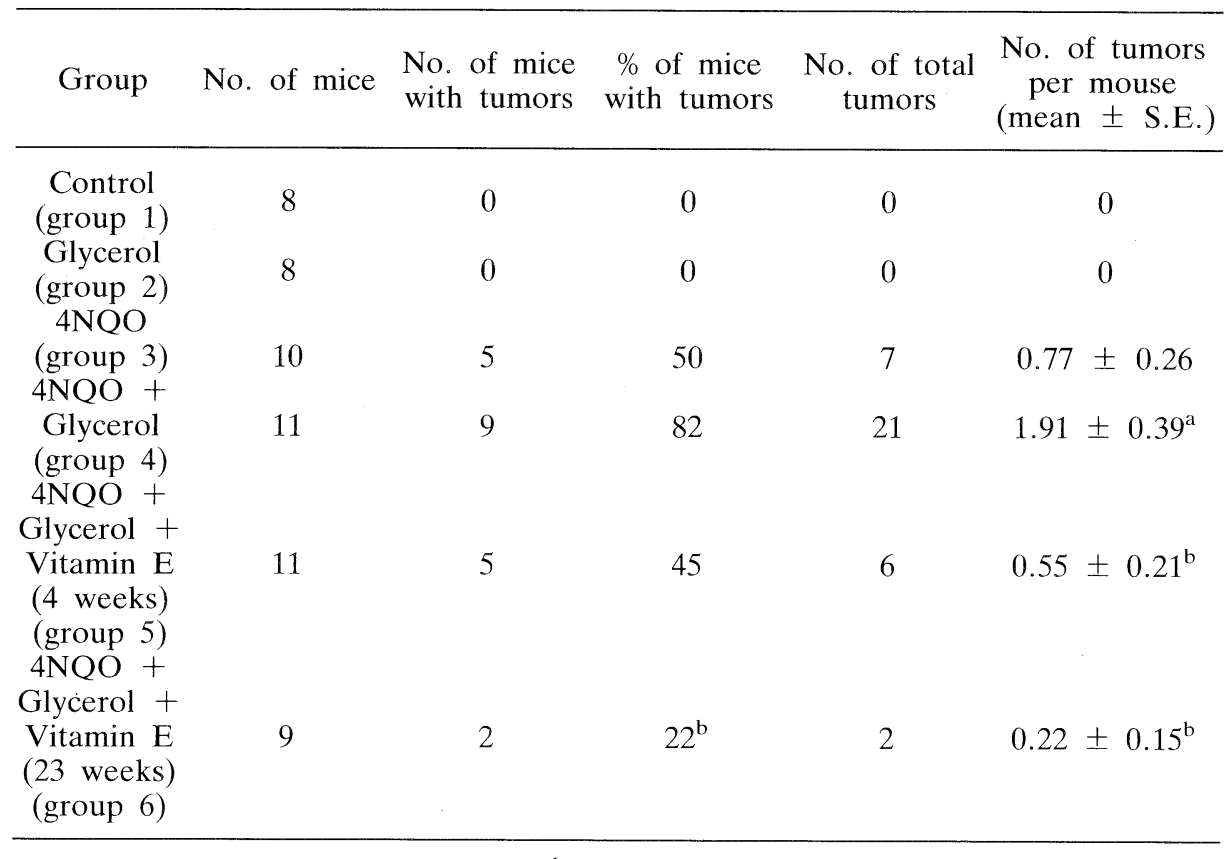

${ }^{a}$ Significant difference from 4 NQO. ${ }^{\mathrm{b}}$ Significant difference from 4 NQO + Glycerol.

treatment completely disappeared through vitamin $\mathrm{E}$ feeding, and the level in the vitamin E-treated group was $20.1 \%$.

Table 2 also shows the prevention of the glycerol-enhanced lung tumorigenesis 
Table 3. The difference of serum vitamin E level among 6 groups.

\begin{tabular}{ccccccc}
\hline $\begin{array}{c}\text { Assay } \\
\text { article }\end{array}$ & group 1 & group 2 & group 3 & group 4 & group 5 & group 6 \\
\hline $\begin{array}{c}\text { Serum } \\
(\mu \mathrm{g} / \mathrm{ml})\end{array}$ & $\begin{array}{c}1.76 \pm \\
0.13\end{array}$ & $\begin{array}{c}1.76 \pm \\
0.12\end{array}$ & $\begin{array}{c}1.70 \pm \\
0.15\end{array}$ & $\begin{array}{c}1.57 \pm \\
0.20\end{array}$ & $\begin{array}{c}2.18 \pm \\
0.14^{\mathrm{a}}\end{array}$ & $\begin{array}{c}4.95 \pm \\
0.59^{\mathrm{b}}\end{array}$ \\
\hline
\end{tabular}

${ }^{\mathrm{a}}$ Significant difference from groups 1 to $4 .^{\mathrm{b}}$ Significant difference from groups 1 to 5 .

by vitamin $\mathrm{E}$ in mice treated with 4 NQO. Feeding on glycerol in drinking water increased the lung tumor incidence by $64 \%$ as well as lung tumor multiplicity by $72 \%$ as compared to the 4NQO-treated group. The feeding on excessive vitamin $\mathrm{E}$ for 4 and 23 weeks after $4 \mathrm{NQO}$ injection to mice treated with $4 \mathrm{NQO}+$ glycerol caused a $45 \%$ and $73 \%$ reduction in lung tumor incidence, and lung tumor multiplicity decrease, to $71 \%$ and $88 \%$ respectively. Additionally, as shown in table 3, the difference in the serum vitamin $E$ level among the groups coincided with the degree of lung tumorigenesis.

\section{DISCUSSION}

Our present study demonstrates that vitamin E protects the lungs against oxy radical-promoted tumorigenesis due to antioxidative and other modifying effects of this vitamin.

Oxidative damage of DNA caused by oxy radicals and pro-oxidant states is likely to be a key factor in carcinogenesis $(3-5)$. We have reported that oxy radicals may have a crucial role in the glycerol-related enhancement of lung tumorigenesis in mice $(1,11)$. The elevated levels of DNA-SSB and nuclear TBARS with glycerol returned to the levels below those in the 4NQO-treated group by the feeding of excessive vitamin $\mathrm{E}$. Additionally, oxy radical-enhanced lung tumorigenesis in mice treated with 4NQO was suppressed by feeding of excessive vitamin $\mathrm{E}$. These findings suggest that vitamin $\mathrm{E}$ can be useful antioxidant to protect nuclei from oxidative stress and oxy radical-enhanced lung tumorigenesis can be inhibited through the preventive effect of vitamin $\mathrm{E}$ on nuclear oxidative stress.

The inhibitory effect of vitamin $\mathrm{E}$ on the glycerol-related enhancement of lung tumorigenesis, was stronger in the group fed vitamin $E$ for 23 weeks than in that fed vitamin $\mathrm{E}$ for 4 weeks. These findings indicate that some physiological functions other than antioxidative function with vitamin $E$ may be effective to suppress the promotion of the development of lung tumors from 4 weeks to 23 weeks after 4 NQO injection. Since the inhibitory effect of vitamin $E$ on the activation of protein kinase $\mathrm{C}(\mathrm{PKC})$, which is a key event in the promotive stage of carcinogenesis (16), has been reported (17), this inhibition can partly account for the suppression of lung tumorigenesis by vitamin $\mathrm{E}$ in mice. However, this 
mechanism requires further study.

The frequency of adenocarcinoma in histological types of lung cancer, is higher in Japan than in western countries (18). In addition, the increased trend of adenocarcinoma may become a serious problem in the near future. The risk factors contributing to lung adenocarcinoma in humans are still unclear, but the present findings suggest that oxy radicals play a considerable role in enhancing lung adenocarcinoma. Since vitamin E can effectively suppress oxy radicalenhanced lung tumorigenesis in mice, vitamin $\mathrm{E}$ may act as a useful agent in the prevention of human lung adenocarcinoma.

This work was supported by a grant from the Ministry of Health and Welfare for the Comprehensive 10-Year Strategy for Cancer Control.

\section{REFERENCES}

1) Yano, T., and Ichikawa, T. (1992): The effect of glycerol and 4-nitroquinoline 1oxide on active oxygen formation in subcellular fractions of lung tissue. Biochem. Pharmacol., 43, 2658-2660.

2) Cerutti, P. A. (1985): Pro-oxidant state and tumor promotion. Science, 227, 375-381.

3) Cerutti, P. A. (1989): Mechanism of action of oxidant carcinogenesis. Cancer Detect. Prev., 14, 281-284.

4) Marnett, I. J. (1987): Peroxy free radicals: potential mediations of tumor initiation and promotion. Carcinogenesis, 8, 1365-1373.

5) Perchelet, J. P., and Perchelet, E. M. (1989): Antioxidants and multistage carcinogenesis in mouse skin. Free Rad. Biol. Med., 7, 377-408.

6) Chen, L. H., Boissonneault, G. A., and Glauert, H. P. (1988): Vitamin C, vitamin $\mathrm{E}$ and cancer (review). Anticancer Res., 8, 739-748.

7) Rogers, A. E., and Longnecker, M. P. (1988): Dietary and nutritional influences on cancer: a review of epidemiologic and experimental data. Lab. Invest., 59, 729-759.

8) Singh, V. W. (1992): A current perspective on nutrition and exercise. J. Nutr., 122, 760-765.

9) Inayama, Y. (1986): Promoting action of glycerol in pulmonary tumorigenic model using a single administration of 4-nitroquinoline 1-oxide in mice. Jpn. J. Cancer Res., 77, 345-350.

10) Inayama, Y., Kitamura, H., Ito, T., and Kanisawa, M. (1986): Effects of glycerol on 4-nitroquinoline 1-oxide induced pulmonary tumorigenesis in ddY mice. Jpn. J. Cancer Res., 77, 103-105.

11) Yano, T., Ishikawa, G., and Ichikawa, T. (1992): A factor contributing to the modulating effect on chemical-induced pulmonary tumorigenesis. J. Toxicol. Sci., in press.

12) Mori, K. (1962): Induction of pulmonary tumors in mice by subcutaneous injections of 4-nitroquinoline 1-oxide. Jpn. J. Cancer Res., 53, 303-308.

13) Uchiyama, M., and Mihara, M. (1978): Determination of malondialdehyde 
precursor in tissue by thiobarbituric acid test. Anal. Biochem., 86, 271-278.

14) Yano, T., Ryu, C., Hagiwara, K., and Ichikawa, T. (1993): The modulating effect of vitamin $\mathrm{E}$ on active oxygen generation by alveolar macrophage challenged with different stimuli. Jpn. J. Toxicol. Environ. Health, in press.

15) Morris, S. R. and Schertzer, H. G. (1985): Rapid analysis of DNA strand breaks in soft tissues. Environ. Mut, 7, 871-880.

16) Nishizuka, Y. (1986): Studies and perspectives of protein kinase C. Science, 233, 305-311.

17) Boscoiboinik, B., Szweczyk, A., Hensey, C. E., and Azzi, A. (1991): Inhibition of cell proliferation by $\alpha$-Tocopherol: role of protein kinase C. J. Biol. Chem., 266, 6188-6194.

18) Yoshimura, K., Yamashita, N., and Ishikawa, H. (1980): Clinical aspects of lung cancer by histological subtypes in Japan. Nihon-Rinsho, 38, 2581-2591. 